\title{
Um modelo dissonante: caracterização e gêneros do jornalismo literário
}

\author{
Mateus Yuri Passos', Romulo Augusto Orlandini?
}

\begin{abstract}
Resumo: Teóricos da Comunicação, Linguagem e Literatura têm abordado obras pertencentes a um agrupamento de gêneros textuais marcados pela hibridização de ambos os campos, a que se tem chamado jornalismo literário ou narrativo, o qual constitui um modelo comunicacional paralelo e antagônico àquele fundamentad่o na cstrutura do lead e pirâmide invertida. Neste artigo, discutimos a teoria de gèneros do discurso desenvolvida por Mikhail Bakhtin para classificar textos de jornalismo literário, levando em consideração as divergências fundamentais que constituem diferentes gèneros discursivos dentro de uma mesma categoria. A partir do entrecruzamento de definições anteriores, sintetizamos cinco elementos essenciais, a partir dos quais se desdobram procedimentos constitutivos das obras (imersão, expansão, precisão, subjetivação e experimentação), c listamos seis gèneros básicos (romance-reportagem, biografia, conto-reportagem, perfil, crônica e carta-reportagem), dos quais se originam outros. Identificamos também o surgimento de variantes e novos gêneros, conforme alteraçios em tema, estrutura de composiçâo e estilo.
\end{abstract}

Palavras-chaves: Comunicação. Jornalismo. Jornalismo literário. Jornalismo narrativo. Gêneros do discurso.

\footnotetext{
Abstract: Communication, Literature and Linguistics authors have focused on works that belong to a cluster of text genres chatacterized by the hybridizing of both fields, which has been named litcrary or narative journalism, a communicational model that parallels and antagonizes the one which bases itself on the lead and inverse pyramid structure. In this paper, we discuss Mikhail Bakhtin's discourse genres theory in order to categorize literary jour-

1 Jornalista graduado ma PUC-Campinas. Isspecialisin em fornalismo Litcrátio pela ABJL/Cesblu. Mestrando en Ciencia, Teconologia e Socicdade na UFSCar. Cursa a cspecializaçào en Jornalismo Cientitico e a graduaçio em Lstudos Literinios na Unicamp. Membro do Labontótio de listudos em Comunicação, Tecnologia e Lducação Cidada - L_LCCOTl:C (Unesp). Bolsista CAPIS. Correio elcurinice: mpassos@irac.unesp.br

2 Jornalista graduado na PUC-Campinas. Mestre em Lingüistica pela UFSCar. Doutorando em Ciencia Politica na UFSCar. Membro do Grupo de Lstudos de Gencros do Discurso - GIEGI: (UFSCar). Bolsista CAPISS. Correio elcurinico: romulo_jornalismo@homail.com
} 
nalism texts, considering fundamental divergences that constitute different discourse genres in a common category. By crossing former definitions, we have synthesized five essential elements (immersion, expansion, accuracy, subjectivization and experimentation) from which some other procedures generate themselves. Thus we list six elementary genres (non-fiction novel, biography, story feature, profile, chronicle and letter feature) from which others may come. We also identify the emergence of new genres and variants according to changes in theme, composition structure and style.

Keywords: Communication. Journalism. Literary journalism. Narrative journalism. Discourse genres.

\section{Introdução}

Naquele mesmo dia haviam morrido milhares de pessoas. Coisa natural e comum é a morte. Também comuns são aqueles que precisam publicizar a dor da perda. Amigos e conhecidos têm que saber - comparecer ao velório, dar o último e derradeiro adeus... $\mathrm{O}$ jornal sempre se prestou a ser um destes porta-vozes fúnebres, trazendo singelamente o nome do falecido. Naquele mesmo dia estava o nome de José Cássio de Barros Penteado. Em uma nota publicava-se que tinha 80 anos, deixara filhos e seria enterrado no cemitério São Paulo. Simples assim. Quando nasceu? O que fez? Quantos filhos deixou? Era bonito? Gentil? Teve alguma aspiração na vida? Gostava de ler? Fazer contas? Foi centro-avante de algum time?... As perguntas vão se construindo às milhares - mas, a não ser que tenhamos a sorte de conhecer algum parente do José, ele se torna um desconhecido que simplesmente teve um lampejo em nossas vidas naquele domingo, naquelas folhas de antemão destinadas ao lixo da segunda.

A tendência de colocar nomes de mortos nos jornais é antiga. O obituário brasileiro, na maioria das vezes, é burocrático. Em outras, recebe destaque e texto mais atencioso. No entanto, essa prática passou a receber maior reconhecimento apenas com Alden Whitman, que no The New York Times tinha como tarefa dar vida a reportagens sobre gente morta, e alcançou excelência com Robert McG. Thomas Jr. (SUZUKI JR., 2008).

No mesmo em que se publicou o óbito de José Cássio, temos a história de Milton Domingos, por Willian Vieira: 
A bengala, o chapéu, o bigode c os pés virados fizeram história na cidade onde nasceu Carlitos de Jundiaí. Scu entcro foi embalado pela própria banda, tocando "Luzes da Ribalta" -a primcira vez que fez alguém chorar.

Milton Domingos se mudou pequeno para São Paulo. Tinha 15 anos quando começou a ver filmes do ator Charles Chaplin passados na parócuia, após a missa. Virou assiduo. "Tinha flexibilidade nas pernas" e juntou a "veia de artista" com os pés virados para fora. Tornou-sc atração na igreja, nas festinhas, $c$ até na empresa onde consertava elevadores. De volta a Jundiaí, lá pelos 20 anos, não parou de imitar. Tinha a roupa negra, o chapéu, a gravata e a bengala. Era só se caracterizar para agradar a uma cidade inteira. "Também trabalhou de verdade", diz a viúva. Era bom vendedor na vinícola, onde se aposentou. Fez até propaganda na TV sobre vinagre.

Já em 1967 era celebridade local, ao vencer o concurso de Melhor Imitador do Brasil, feito por Silvio Santos. Desdc então passou a animar de festa a jogos de futcbol. Como Carlitos, se apresentou no teatro e no cinema encenou " $\mathrm{O}$ Ébrio" e gravou "Crepúsculo do Ódio". E fez até ponta cm novela, com a Banda do Carlitos, criada por cle para animar festas.

Tinha tres filhos e dois netos. Quando fez 60 anos de carreira, em janciro, ganhou uma mostra na biblioteca. Não foi ver. Morreu no dia 1", aos 75, de cancer. (VIEIRA, 6 abr. 2008, p.12)

Um fato incomum é um texto semelhante ao perfil ter sido publicado na Folha de S. Pahlo, jornal que dificilmente comporta esse tipo de linguagem (FALASCH1, 2005). Uma explicação possivel para sua presença é a tradição do uso de textos mais criativos nos jornais, especialmente nas edições dominicais, com destaque para o uso da estrutura de crônicas (cf. SAVIANI REY, 2007; BAHIA, 1990), embora neste caso a Folla publique obituários desse feitio diariamente desde 31 de outubro de 2007, o que constitui a mais recente novidade estrutural do veiculo (MAGALHȦES, 2007).

$\Lambda$ tentativa de se fazer um obituário em termos menos formais pode ser compreendida no contexto da retomada do jornalismo lite- 
rário (ou narrativo) no Brasil em diversas iniciativas editoriais desde 2003. Além de coleções de livros e revistas (dentre elas piauí, Brasileiros e Rolling Stone Brasil) dedicadas à sua prática, jornais de prestígio, em especial Correio Brasiliense, Zero Hora e O Estado de S. Paulo, dedicam cada vez mais espaço a reportagens narrativas, revertendo sua queda de circulação, como aponta Falaschi (2005).

Um dos primeiros a teorizar sobre o jornalismo literário, Tom Wolfe (2005) aborda-o como ruptura com os modelos jornalísticos então vigentes, embora já admita precursores como Joseph Mitchell e John Hersey. A visão da crítica norte-americana dos anos 60 e 70 sobre o que então se chamava Novo Jornalismo trazia, já na designação, esse caráter de novidade, rompimento com um passado. Rildon Cosson (2007) identifica que, por outro lado, manifestações semelhantes no Brasil, com as reportagens de Realidade, Jornal da Tarde e romancesreportagem imbuíam-se, de acordo com críticos e praticantes, no resgate de uma "boa narrativa", ou seja, na filiação ao passado. A crítica norte-americana atual traça o início do jornalismo literário até o final do século XIX (CONNERY, 1992), com Stephen Crane, e aponta como pioneiros alguns escritores e jornalistas do século anterior, principalmente Daniel Defoe e James Boswell (KERRANE \& YAGODA, 1997). Descreve-se, assim, uma tradição jornalístico-literária da qual o Novo Jornalismo seria não o estopim, mas uma fase ou movimento.

É questionável, porém, classificá-lo como um subgênero do jornalismo a que chamaríamos tradicional, cujas fundações baseiamse na distinção entre informação e opinião (de que derivariam os "gêneros" informativo e opinativo) e num cientificismo positivista, tendo suas variedades informativas desenvolvidas a partir da fórmula do lead e da estrutura de pirâmide invertida. Mário Erbolato enquadra o jornalismo literário (a que denomina "jornalismo diversional") dentro da corrente predominante como um gênero que contempla uma escrita "leve, original e agradável" (2001, p.44), que permitiria relativo embevecimento e a contemplação de temas que escapam aos bard news, função também atribuída à crônica. Todavia, o principal exemplo citado por Erbolato - o romance-reportagem $A$ Sangue Frio, de Truman Capote - tem como mote o assassinato da família Clutter, num tratamento denso, o que já contraria a caracterização proposta.

Outro problema é a idéia de que o jornalismo literário se constitui de uma unidade de proposta formal e discursiva, ou seja, de que compõe um conjunto coeso de textos e repórteres-escritores de ten- 
dências semelhantes. A contenda de autores como Lillian Ross e Norman Mailer contra sua classificação sob o rótulo do Novo Jornalismo, como propõe Wolfe (2005), é um exemplo de conseqüência dessa opção. Mailer rejeita a profissão de jornalista, 'modo promíscuo de ganhar a vida' (2006, p.11), e, a despeito de trabalhar em ritmo mais rápido que o comum para a profissão, considera-se escritor dentro da tradição literária de língua inglesa, embora enfoque temas factuais e, em Miami e o cerco de Cbicago, denomine a si mesmo "repórter" enquanto personagem. Ross (2002), por outro lado, afirma desafiar estruturas noticiosas tradicionais, mas rejeita qualquer aproximaçào com a literatura, não utilizando a primeira pessoa e afirmando não emitir opiniões. É possivel que se obtenha uma melhor compreensão desses autores dentro de uma tradição ao se destacar e valorizar a pluralidade compreendida no conjunto, em vez de uma coesão poucas vezes verificável.

Abordamos, dessa forma, o jornalismo literário como um conjunto composto por diferentes categorias textuais e gêneros discursivos, que não se configura como pertence ou variação do jornalismo predominante, mas um modelo paralelo e oposto, composto de suas próprias variações de modalidade, e cujo fundamento, como aponta Cosson $(2001 ; 2007)$, é a hibridizaçào estrutural e discursiva entre jornalismo e literatura.

Neste artigo, discutimos a teoria de gêneros do discurso desenvolvida por Mikhail Bakhtin para, a partir de uma confrontação com os gêneros literários estabelecidos da caracterização desse modelo jornalístico dissonante, propor categorjas não estáticas, mas a partir das quais seja possível classificar textos que se enquadrem como obras do jornalismo literário, levando em consideração os elementos essenciais que o definem e caracterizam e as divergéncias fundamentais que constituem diferentes gêneros discursivos de jornalismo literário dentro de uma mesma categoria.

\section{Gêneros do discurso e jornalismo}

Os estudos de linguagem de Bakhtin (1997) privilegiam os signos à luz de processos sociais. Bakhtin prega que um signo é constituído de um significado e um significante (estrutura mental), porém há mais do que isso. Deve-se levar em conta uma série de fatores, como o contexto dos enunciados. 
Os signos emergem e significam no interior das relações sociais, estão entre seres socialmente organizados, não podem assim, ser concebidos como resultados de processos apenas fisiológicos e psicológicos de um indivíduo isolado, ou determinados apenas por um sistema formal abstrato. Para estudá-los é indispensável situá-los nos processos sociais globais que thes darão significação. (BAKHTIN apud FARACO, 2003, p.48).

Assim, leva em conta o social enquanto materialismo sóciohistórico. Dos termos que cunhou, ganha destaque o dialogismo:

Bakhtin (...) considera o dialogismo o princípio constitutivo da linguagem e a condição do sentido do discurso. Insiste no fato de que o discurso não é individual, nas duas acepções de dialogismo mencionadas: não é individual porque se constrói entre pelo menos dois interlocutores, que, por sua vez, são seres sociais; não é individual porque se constrói como um "diálogo" entre discursos, ou seja, porque mantém relações com outros discursos (BARROS, 2005, P.32).

O princípio dialógico é simplesmente levar em conta o interlocutor, num processo de alteridade constitutiva. É um diálogo permanente após uma enunciação, que leva em consta a visão do outro sobre eu e também do outro sobre o outro. Assim, o eu completo só se dá no outro, no jogo de relações sociais. Ao dizer que tudo pode ser um signo, entende-se que este pode carregar consigo referências somente entendidas no jogo social, na relação entre as pessoas (ou sujeitos), afinidade essa que sustenta a linguagem:

Tudo o que é ideológico possui um significado e remete a algo situado fora de si mesmo. Em outros termos, tudo que é ideológico é um signo. Sem signos não existe ideologia. Um objeto vale por si próprio: não significa nada e coincide inteiramente com sua própria natureza (1997, p. 31).

Portanto, a palavra seria o palco de uma arena de luta, onde as ideologias vão sendo constituídas nas tessituras sociais e acabam tefletidas e refratadas. Nenhum discurso é novo; tudo faz parte de uma corrente na qual há um "antes" e um "depois". Cada palavra carrega consigo a possibilidade de agregar significados, cada vez mais sentidos 
sem deixar de lado os sentidos antigos. Porém, não são somente as palavras que podem ter significados. Tudo pode ser entendido como signo, sendo que três fatores o constitucm: momento histórico, contexto c memória. Desse caldo podemos tomar que cada signo é regido sob a égide dessas três instâncias, a fim de obter um entendimento social.

Bakhtin dá como pressuposto que é a linguagem o principal anel que une diferentes instâncias da realidade. Assim, todo discurso enunciado faz parte de um elo de uma corrente - não existindo assim un enunciado adâmico (que se fez sozinho). No entanto, ao reformularmos um enunciado, atendemos a necessidade do momento da enunciaçào, refletindo as condiçoèes especificas e as finalidades da esfera de atividade humana em que estamos inseridos; essa delimitação é chamada de gênero do discurso (BAKHTIN, 1997). Dessa maneira, define que os gêneros são infinitos na medida em que as atividades humanas são incomensuráveis, mas podem ser definidos através de três distinções: conteúdo temático, estilo e construçào ou estrutura composicional.

O gènero sempre é e não é o mesmo, sempre ć nowo e velho ao mesmo tempo. O genero renasce e se renova em cada nova etapa do desenvolvimento da litcratura e em cada obra individual de um dado gènero. Nisto consiste a vida do gênero (BAKHTIN, 1997, p.106).

Para entender as separações que os compõem, o primeiro passo é entender as separações entre os gêneros, delimitados em primários e sechndarios. Enquanto o primeiro é o simples diálogo (informal), que está mais presente na realidade concreta do cotidiano, o segundo é formado pela aglomeração do discurso oficial (documental). 'Durante o processo de sua formação, esses gêneros secundários absorvem e transmutam os gêneros primários (simples) de todas as espécies, que se constituiram em circunstância de comunicação verbal espontânea' (BAKHTIN, 1997, p. 281).

Dividido entre informação e opinião, o jornalismo convencional comporta dois gêneros discursivos diversos, que foram se constituindo não apesar um do outro, mas, sobretudo, a partir um do outro. A dicotomia que poderia ser vista entre os "dois jornalismos" não é nada mais que as identidades de cada gènero arquitetadas principalmente através do diálogo. 
Como afirmamos anteriormente, estamos imersos nos mais variados gêneros do discurso. Eles nos constituem e nós os constituímos. Definimos nosso público-alvo a cada instante no universo comunicacional. Um traço essencial para se formar um gênero, segundo Bakhtin (1997), é tomar o direcionamento ou endereçamento do enunciado. Isso é de fundamental importância a cada novo empreendimento comunicacional: escolher o gênero com o qual iremos falar, a partir da situação em que estamos; com quem e com quais finalidades o fazemos, ou seja; o contexto. Não tomamos a palavra em seu sentido "neutro", dicionarizado: A partir da circunstância optamos pelo estilo da fala, tema, forma, entonação expressiva, ou seja, escolhemos inconscientemente uma estratégia discursiva.

Então temos diante de nós um todo relacional quando falamos - ou escrevemos. Pensamos linguagem no âmbito das realidades cotidianas e não mais como gramáticas estáticas. Ao enunciar, temos no pensamento como será a compreensão e buscamos prever respostas. 'O próprio sujeito desloca-se, no tempo, e estabelece no futuro a razão de ser de sua ação presente, que, concretizada, torna-se pré-dado para futuras ações, sempre orientadas pelo sentido que lhe concede a razão, perpetuamente situada à frente' (GERALDI, 2003, p.45).

Portanto, no processo já não há mais aquele esquema ficcional (cf. BAKHTIN, 1979) de emissão e recepção. Através dos elementos relativos ao texto, o jornalista introduz-se no fato e traz para o leitor, por meio da literariedade, possibilidades novas para um texto jornalístico.

\section{Jornalismo literário: caracterização}

A primeira caracterização do que viria a ser conhecido como jornalismo literátio foi proposta por Tom Wolfe em 1973, com base na presença de elementos do realismo social em reportagens publicadas principalmente em revistas e em livros-reportagem elaborados como romances. Aí já se lançava a noção, a partir de então difundida, de que o "novo" modelo combinava elementos não apenas técnicos, mas também cognitivos da literatura e do jornalismo.

Propusemos anteriormente (cf. PASSOS \& ORLANDINI, 2007) uma comparação estrutural entre o jornalismo literário e o modelo lead, com base em Roland Barthes. Podemos compreender a diferença fundamental entre os dois modelos da seguinte maneira: no último prevalecem os dados e ações primários de um aconteci- 
mento. No jornalismo literário, os mesmos ainda são contemplados, mas há um procedimento de preenchimento, com a adição de informações indiciais e ações catalíticas, menores, constituindo um registro expandido da realidade. Assim, o modelo predominante se configura por um procedimento que propomos denominar centripeto, pois há um movimento em direção ao núcleo informacional, com foco nos resultados imediatos do fato; em contrapartida, o jornalismo literário é essencialmente centrífugo, partindo do mesmo núcleo para encontrar correspondências anteriores e contemporâneas, tangenciais e paralelas, inclusive possiveis desdobramentos futuros. O foco aí se dá nos processos, na vida humana em movimento.

Não são palavas o que pronunciamos ou cscutamos, mas verdades ou mentiras, coisas boas ou más, importantes ou triviais, agradáveis ou desagradáveis, ctc. $\wedge$ palavra está sempre carregada de um conteúdo ou de um sentido ideológico ou vivencial. É assim que compreendemos as palavras c somente reagimos aquelas que despertam cm nós ressonancias ideológicas concernentes à vida. (BAKHTIN, 1997, p.95)

Desse modo, em jornalismo literário os enunciados se assumem não como agrupamentos de palavras objetivas, mas de sua subjetivação, de suas ressonâncias para a vida.

Vemos surgir um grupo de escritores (...) que descobrem as alegrias dorealismo detal hado o seus estranhos poderes. Muitos deles parecem estar apaixonados pelo "realismo pelo realismo" apenas; c não se importar com "o sagrado chamado" da litcratura. Parecem dizer: "Ei! Venha cá! E assim que as pessoas vivem agora - bem assim como estou mostrando a vocé! Pode assustar, incomodar, deliciar você ou despertar seu desprezo ou fazer vocé rir..." (WOLFE, 1995, p.48-49)

É o que encontramos $\mathrm{cm} A$ sangue frio (CAPOTE, 2003): não apenas a informação de que a familia Clutter, de Holcomb, Kansas, foi assassinada, mas também cenas do último dia de suas vidas, a trilha e os percalços que levaram os assassinos até o dia fatídico, bem como sua fuga c o processo de investigação que lcvou a sua captura, prisão c morte. 
Essa relação de tensão entre forças centrípetas e centrífugas é baseada nos poderes das ideologias oficiais e dos cotidianos circunscritos na sociedade (SILVESTRI, 2006, p.28). Existem meios de comunicação que professam o regime oficial, tendendo a assentar que a linguagem não é o local da mudança e, por isso, o leitor pode confiar plenamente naquilo que lê porque realmente aconteceu, de uma maneira objetiva, porém idealista - é A história (modelo tradicional). Já as forças centrífugas nos levam para uma relação na qual a humanização ou subjetivação do discurso jornalístico é um fator considerado a priori. Toma de pronto que as reportagens são possibilidades textuais mediadas por um repórter, que antes de tudo é um sujeito com uma bagagem ideológica. Ele conta UMA história (jornalismo literário).

Por isso, a definição de Silvestri é muito benéfica para termos a coragem de pedir licença para a física e usarmos tais conceitos. Enquanto o discurso oficial nos tende a jogar para dentro de um texto cuja estrutura já é pré-dada e os sentidos amortizados, o jornalismo literário dá a possibilidade de sermos jogados para fora. Esse exterior é que constitui um outro caráter, diferente daqueles tidos como somente informativos ou opinativos. É um entremeio, interpretativo, cuja certeza é encontrar o diferente como identidade. Não podemos e não devemos nos esquecer que cada repórter possui uma vida própria antes e depois de sair da redação. Assim, não se desgruda da realidade social em que está imbricado e manifesta sua identidade, ou corporeidade, em cada obra.

A união carne/intelecto é a centrifugação, o esparramar por todas as estrias do sistema de comando as qualidades humanas. A corporeidade é construção de corpos singulares os quais, com seus afetos, criam bandos, maltas não hierarquizadas por essência. (...) são os novos bárbaros. (SILVESTRI, 2006, p.176).

A sistemática jornalística informativa é muito definida e delimitada no próprio espaço físico do jornal. Assim, opinião fica de um lado, publicidade de outro e jornalismo "sério" de outro. Isso faz parte do modelo tradicional da imprensa, cujo tema são notícias, a estrutura é a de pirâmidé invertida e o estilo eminentemente desprovido de adjetivação e variações de elementos textuais, que não ratamente engessam e deixam o texto asséptico. Já a proposta de jornalismo literário mostra que a mutabilidade dos gêneros é a força constitutiva 
desse modelo. Como no texto de Willian Vieira que abre este artigo, ao ser diferente dentro da fórmula do obituário, a reportagem ganhou uma força imensa ao narrar uma história de vida, mesmo que singela. Como afirma Silvestri, esparrama-se por dentro do sistema já constituído e pode causar uma alteraçào de orientação de uma trajetória centrípeta para centrifuga.

Talvez cste scja um tempo em que as imagens que projetamos do futuro tenham deixados de nos ver porque nós, vivendo o presente de uma ordem mundial globalizada e assentada no movimento de capitais virtuais e de scus lucros, deixamos de enxergar quaisquer caminhos alternativos de construção de uma nova ordem. (GERALDI, 2003, p.40).

Para constituir uma caracterizaçào do jomalismo literário, tomamos como base os elementos propostos por Tom Wolfe, Norman Sims, Mark Kramer e Felipe Pena. Os autores apresentam, sob diferentes perspectivas, itens que compòem o todo do modelo: classificálos-emos como anteriores ou imanentes ao texto e interacionais-teceptivos, agrupamentos que discutiremos a seguir.

Ao abordar as caracteristicas do Novo Jornalismo, Wolfe (2005) registra os quatro principais elementos do realismo social: a construção de acontecimentos cena a cena, o registro de diálogos completos (cm vez de se urilizar falas ilustrativas), a descrição de pessoas e ambientes de modo a simbolizar seu status de vida e o uso de pontos de vista. Sims e Kramer (1995) identificam sete: imersão do repórter na realidade ou assunto abordado, uso de voz autoral, estilo literário, precisão de dados e informações, uso de símbolos e metáforas, digressão e humanização. Por fim, Pena (2006) propõe uma "estrela de sete pontas" que reúne princípios deontológicos da prática jornalistica nesse modelo: potencializar os recursos do jornalismo, ultrapassar os limites do acontecimento cotidiano, proporcionar uma visão ampla da realidade, exercitar a cidadania, romper com as correntes do lead, evitar os definidores primários e buscar a perenidade do texto.

Podemos reduzir o conjunto a cinco elementos essenciais, dos quais se desdobrarão os procedimentos elencados: imersão, expansão, precisão, subjetivaçào, experimentação. Devemos esclarecer que precisão não corresponde necessariamente à excessiva referenciação, 
mas ao caráter descritivo-indicial das narrativas, levando em consideração as observações de Cosson (2007) e Resende (2002) do uso de notações informacionais vagas por Tom Wolfe e autores de romances-reportagem brasileiros; por subjetivação ou subjetividade não denotamos emissão de opiniões de forma indiscriminada ou sem embasamento, mas o status que repórter e fontes de informação adquirem, tornando-se, em vez de objetos, sujeitos, narrador e personagens; por fim, com experimentação não nos restringimos a rompimentos formais, mas qualquer exploração dos recursos da linguagem que, como aponta Bulhões (2007), é inerente à literatura e fundamental àquelas produções que se pretendam literárias.

\section{Elementos anteriores ao texto}

Por elementos anteriores ao texto designamos aqueles relativos à preparação da narrativa, previamente ou durante a atuação do repórter em campo. Embora relacione-se de modo geral aos domínios da imersão e expansão, a tomada de decisões relacionada nessa etapa (inclusive a escolha de fontes e o caráter das entrevistas) influirá diretamente na viabilidade dos três demais.

De um modo geral, a etapa compreende a imersão, pesquisa intensiva ou exaustiva somada à convivência (e em muitos casos, vivência) com o tema e personagens sobre quem se escreverá, em longas entrevistas e no acompanhamento de atividades rotineiras.

A imersão no tema permite atender de pronto a duas das diretrizes propostas por Felipe Pena (2006): ultrapassar os limites do acontecimento (ou do jornalismo) cotidiano (imediatista), angariando material para expandir seus limites temporais, e evitar os definidores primários, fontes já legitimadas, como pesquisadores de universidades renomadas. Evitar definidores primáriơs implica em buscar fontes alternativas, ouvir pontos de vista menos abordados pela imprensa diária, o que demanda pesquisa (inclusive em campo) de qualidade. Também é aqui que se permite o exercíció de cidadania; ou seja, quando um repórter tem em mãos um tema, 'deve pensar em como sua abordagem pode contribuir para a formação do cidadão, para o bem comum, para a solidariedade' (PENA, 2006, p.14), o que demandará opções que nortearão a composição formal da obra. 


\section{Elementos imanentes ao texto}

Por elementos imanentes ao texto refcrimo-nos àqueles cuja materialidade se expressa na construção textual, ou seja, tratam principalmente de procedimentos formais, a partir dos quais as missões de polencializar os recursos do jornalismo e romper com as correntes do lead (PENA, 2006) podem ser cumpridas. Trata-sc, especificamente, da possibilidade de uso de uma variada gama de recursos literários: voz autoral, figuras de linguagem, cenas em seqüência, diálogos, pontos de vista $\mathrm{c}$ a descriçáo dos personagens c seus "cenários", o que pode transmitir seu status de vida. Todos esses procedimentos participam também do processo de subje tivação.

Embora Wolfe pretenda affliar o Novo Jomalismo à correntc naturalista da litcratura, o modelo é livre para abarcar procedimentos do simbolismo e demais momentos literários, como monólogo interior, neologismo, referências externas, rima, paródia, rompimcntos de niveis, relativização de perfis (cf. PASSOS, 2006), intertextualidade, polifonia e onomatopéias. Ao analisar os romances-reportagem brasileiros da década de 1970, Rildo Cosson (2001) identifica ainda a recordação (ou flasłback), motivaçño psicológica, validaçào do discurso, circulação de informação, reprodução de outros discursos e localização espacial. $\Lambda$ digressão, já identificada em narrativas jornalísticas por Sims e Kramer (1995), permitc tambćm a cxpansão do relato para acontecimentos e caracterizações relacionados ao tema ou personagem principal.

Por fim, recursos de precisão (como a datação) e a utilização apenas de informações verídicas $\mathrm{c}$ verificadas ancoram a obra ao domínio jornalística e garantem sua credibilidade.

\section{Elementos interacionais-receptivos}

Tratamos por clementos interacionais-receptivos aqueles de caráter hermenêutico, existentes por meio da recepção do tcxio $c$ de sua interação com o leitor: Aqui é que se verifica se foram atendidos os princípios de se proporcionar uma visão ampla da realidade $c$ de atingir-se a perenidade, o que se verificará pelo "tempo de vida" da obra, inclusive em sua recepção crítica e possivelmente a ocupação de uma vaga em um cânone.

Deve-se considerar aqui também efcitos da narrativa, como a humanização e a imersão do próprio leitor na realidade representada, permitindo-the vivenciar aquilo que foi percebido pelo autor. 


\section{Alguns gêneros do jornalismo literário}

Recordando a afirmação de Bakhtin (1997) de que um gênero discursivo se constitui por um tema, uma estrutura composicional $\mathrm{e}$ um estilo característicos, e que, portanto, qualquer variação em um desses elementos acabaria por gerar um novo gênero. Assim, podemos compreender como obras com estruturas e temas semelhantes, versando, por exemplo, sobre personalidades do mundo artistístico, como as de Lillian Ross, Tom Wolfe e Gay Talese, ou político, como as de Norman Mailer, Hunter S. Thompson e Fernando Morais, diferem tanto em estilo e discurso que podem ser considerados pertencentes a gêneros ou correntes distintas dentro do conjunto maior do jornalismo literário.

Considerando a impossibilidade de se restringir um número de gêneros, dadas as infinitas possibilidades de mutação de temas, estilos e construções composicionais, partiremos destas para delimitar ao menos classificações textuais dentro das quais variações estilíticas e temáticas darão vazão a inúmeros gêneros litero-jornalísticos. Listamos abaixo sete categorias básicas, verificadas em publicações, que não esgotam as possibilidades composicionais em jornalismo literário, mas, partilhando de um movimento centrífugo, de expansão, servem de modelo comparativo para se definir outras estruturas.

Outras propostas de classificação, especificamente voltadas ao suporte livro, são apresentadas por Edvaldo Pereira Lima em Páginas Ampliadas (2004).

\section{Romance-reportagem}

Mescla entre dois gêneros consagrados, tem em sua constituição a factualidade inerente ao jornalismo bard news, porém trabalhada com traços românticos (mas que tendem a um certo simbolismo, principalmente por fazer uso da psicologia para definir personagens e atos). Cosson (2001) define o conceito como "em trânsito", não apresentando uma divisão plena entre realismo e ficcionalidade. Em geral trabalha com mais de um núcleo de personagens, trabalhando consideráveis deslocamentos no tempo e no espaço, embora não abarquem vidas inteiras, como a biografia.

São exemplos Os Sertões, de Euclides da Cunha, Abusado e Rota 66, de Caco Barcellos, Lúcio Flávio, de José Louzeiro, O teste do ácido do refresco elétrico e Os eleitos, de Tom Wolfe, Hiroshima, de John Hersey, 
A sangue frio, de Truman Capote, Os bonrados mafiosos, de Gay Talese, Os exércitos da noite, de Norman Mailer, e $O$ mandarim, de Eustáquio Gomes. Algumas obras dessa categoria, como as de Ross, Capote, Mailer e Gomes, foram serializadas em revistas ou jornais antes de adquirirem sua feição final em livro; tal prática pode ser considerada uma espécie de folhetim-reportagem, semelhante aos romances publicados em capitulos no século XIX (BULHÕES, 2007).

\section{Biografia}

Sào obras, geralmente em suporte livro, que se propõem a dar conta de uma vida inteira, com suas diversas etapas e peripécias, geralmente em seqüencia cronológica. São exemplos $O / g a$, de Fernando Morais, Estrela Solitária, de Ruy Castro, Marylin, de Norman Mailer, e Uma mente brillante, de Sylvia Nasar. Obituários como o que apresentamos no início, bem com os praticados por jornais como Tbe New York Times, são variaçōes curtas de biografias que têm como ponto de partida a morte do personagem.

Conto-reportagem

Apresenta uso de narrativas que apóiam a trama, expressōes populares, situação dramatizada, sem foco em estatísticas. Segundo Sodré \& Ferrari (1986), duas marcações apresentan-se como desenho geral do conto-reportagem: na maioria das vezes, figura somente um personagem na história e o texto tem um tom de anedota interiorana, sem maldade. Geralmente busca contar uma história por um lado pitoresco e curioso, deixando como pano de fundo da carga lírica a situação em si - muitas vezes cruel. Tende para um final marcante e apresenta concisão temporal e espacial.

São exemplos textos de Vanessa Barbara e Raquel Zangrandi e Luiz Maklouf Carvalho para piani, Grä-finos em Sño Paulo, de Joel Silveira, e as coberturas de convenções presidenciais em $O$ super-bomem wai ao supermercado, de Norman Mailer.

A maior parte das produções gonzo de Hunter $\mathrm{S}$. Thompson, como O Kentucky Derby está decadente, podem ser compreendidas como contos-reportagem. O gonzo já é compreendido como gênero, com suas peculiaridades discursivas, praticamente restritas a Thompson. 
Textos (em suporte livro ou periódico) que, além de serem originados de técnicas de apuração jornalísticas, têm seu percurso discursivo, bem como construção composicional, estruturados sobre a defesa de uma idéia ou ponto de vista, muitas vezes expressando de forma mais evidente opiniões pessoais dos autores.

São exemplos 1968: o ano que não terminou, de Zuenir Ventura, O verde violentou o muro e Veia bailarina, de Ignácio de Loyola Brandão, e Hell's Angels: medo e delirio sobre duas rodas, de Hunter S. Thompson.

Perfil

Ao contrário da biografia, o perfil não pretende descrever por completo uma vida, mas apresentar num recorte temporal as características; valores e o modo de vida de um personagem, numa estrutura semelhante à do conto, porém cujos elementos se orientam para a caracterização do protagonista. Obras de outras categorias podem conter mini-perfis, descrições que pretendam oferecer um "instantâneo" de um indivíduo (VILAS BOAS, 2003).

São exemplos O professor gaivota, primeiro texto sobre Joe Gould de Joseph Mitchell, How do you like it now, gentlemen?, de Lillian Ross, Frank Sinatra está resfriado, de Gay Talese, e The mountains of $P_{i}$, de Richard Preston.

\section{Crônica}

Assumiu uma caracterização própria no Brasil, em que se afirmou sua identidade discursiva no jornalismo (SAVIANI REY, 2007). Também encampada pelo modelo tradicional, há um dissenso sobre seu enquadramento enquanto material opinativo ou informativo (MELO, 2006).

Enquanto categoria do jornalismo literário, oferece uma apreciação, ou epifania, a respeito de algum assunto ou personagem, assumindo por vezes um tom educativo. Tem entre seus praticantes Nelson Rodrigues, Carlos Heitor Cony, Rubem Braga e Eliane Brum que na série $A$ vida que ninguém vê apresenta um híbrido de crônica e perfil, tratando de personagens à margem da sociedade. Saviani Rey (2007) apresenta classificações distintas de crônicas de açordo com sua orientação discursiva. 
As manobras de exploração da linguagem, por vezes, permitem a elaboração de novos modos de composição. Embora ao menos desde o Werther de Goethe haja peças literárias que utilizam a carta como procedimento constitutivo de sua forma, no jornalismo essa prática ainda é um tanto incipiente.

Há uma operação, por um lado, de apropriação da identidade e ponto de vista de um sujeito ou personagem; por outro, de um apagamento do narrador. Assim, o repórter, enquanto falante, assume totalmente o lugat discursivo de um outro, buscando não apenas reproduzir suas ideologias, mas promover um diálogo, quando não um enfrentamento, com outra.

En 12 de junho de 2005 , Fred Melo Paiva publicou em O Estado de S. Paulo a carta-reportagem Carissima Eliana, "endereçada", em nome da comunidade da favela Coliseu, a Eliana Tranchesi, proprietária da butique Daslu, que dela se avizinha. Sem assumir a voz de um único personagem, mas do coletivo, o repórter, na época da inauguração da loja, aptesenta os contrastes do luxo de uma e da miséria da outra.

\section{Variações e inovações - à guisa de considerações finais}

Bakhtin foi inovador ao estudar a prosificação no romance como forma de representação da voz de homens que emanam uma ideologia. Por excelência, esse seria o local de possibilidades combinatórias, naquilo que podemos entender como um meio dialogizante. Para ele, os gêneros discursivos são dimensionados de acordo com as formas como as culturas se apresentam ao longo dos tempos (MACHADO, 2005). Assim, não podemos ignorar que, em jornalismo literário, que uma categoria abarcará diferentes gêneros também em função do contexto temporal e espacial, ou seja, social em que se cada texto foi elaborado - dai obras tão diversas como Os Sertòes, Abusado e Os exercitos da noite poderem, enquadrando-se na categoria romance-reportagem, poderem ser compreendidas como discursivamente díspares.

Estudos especificamente voltados ao jornalismo literário têm se desenvolvido desde a década de 1960 , com o advento do Novo Jornalismo, e, embora a discussão em torno do tema tenha adquirido 
maior maturidade, ainda há problemas de teoria e historiografia a se pesquisar e modelos de solução a propor - dentre eles sua própria denominação, que ainda hoje passa por variantes como jornalismo narrativo, jornalismo informacional de criação, jornalismo diversional e literatura da realidade.

Dentro do estuido de gêneros do discurso, ainda podemos pontuar aqueles que não se enquadram nas categorias apresentadas. Nos anos 1960, Jimmy Breslin saiu às ruas para escrever suas colunas no Herald Tribune (Wolfe, 2005), como fez Eliane Brum no Zero Hora no início dos anos $2000 \mathrm{em} A$ vida que ninguém vê, reunida em livro em 2006. Embora classificada aqui como crônica, estudos posteriores podem assinalar tal composição mesclada ao perfil como representante de outra categoria.

O desenvolvimento e a verificação efetiva, nos meios de comunicação, de novas variações que experimentem outras possibilidades dircursivas, por exemplo a forma do cordel - como proposto por Isabel de Assis Fonseca (2006) - e a não linearidade do hipertexto, de forma a apresentar estruturas completamente distintas das demais.

Além disso, pode-se averigüar o modo como histórias de quadrinhos não-ficcionais, como o Maus de Art Spiegelman (cujo protagonista realiza entrevistas com o pai para resgatar sua história no Holocausto), Pyongyang, de Guy Delisle (um relato de sua estada na capital da Coréia do Norte) e as obras de Joe Sacco (cf. OLIVEIRA \& PASSOS), declaradamente jornalísticas, se aproximam do modelo do jornalismo literário - e, caso efetivamente sejam incorporadas por ele, há de se repensar (e expandir) a própria natureza do conjunto, de modo a englobar outras manifestações da linguagem além da puramente textual.

No jornalismo literário, os gêneros comportam um sujeitotexto humanista, ideologizado, sensivel. Sabemos que essa espécie de jornalismo não é o predominante, principalmente nos grandes veículos de comunicação - mas, se o ressurgiu no final do século XX, foi porque a sociedade deu conta que havia possibilidade dele ganhar força novamente.

Portanto, aproximar jornalismo literário e teoria de gêneros do discurso, buscando estreitar características temáticas e estilísticas, se torna uma maneira de mostrar que, distante de uma padronização deformacional do jornalismo convencional, por meio da diferença é possivel encontrar uma identidade. Com a obtenção de um direito à 
informação, o leitor busca agora o horizonte para novas possibilidades de compreensão, que fogem de orientações não-assumidas e posições veladas e dão margem à reflexão que permitirá um novo percurso. Geraldi (2003) emprega uma imagem bela para dizer o mesmo: pesquisamos detalhes (palavras) em uma floresta (linguagem) para depois retornarmos ao início. A floresta é a mesma, nós somos os mesmos, porém a viagem de volta não é um retorno - é uma outra viagem.

A grande variedade a que os repórteres se lançam - personalidades, anônimos, esportes, crimes, tragédias, ciência, artes, moda, politica - ou seja, a infinitude de assuntos que surgem cotidianamente, é a matéria-prima do jornalismo literário. A utilização do termo centrifugo demonstra a possibilidade infinita que os gêneros podem se constituir, construir e reconstruir durante as relações sociais a cada instante, sem um controle definido e definitivo. Enquanto o método anterior, o centripeto, derivava para um destino certo, a centrifugação é a certeza da variação, lugar do novo, de novas possibilidades. No campo do jornalismo, é o lugar para alargar as margens textuais para o sujeito-repórter, para novas temáticas, novas estruturações e novos modos de arriscar, talvez, uma nova sociedade. 


\section{Referências}

BAHIA, Juarez. Jornal, história e técnica. São Paulo: Ática, 1990. BULHÕES, Marcelo. Jornalismo e literatura em convergência. São Paulo: Ática, 2007.

BAKHTIN, Mikhail. Marxismo e filosofia da linguagem. Tradução de Michael Lahud e Yara Frateschi Vieira. São Paulo: Hucitec, 1979. na Galvão Pereira. São Paulo: Martins Fontes, 1997. Estética da criąão verbal. Tradução de Maria Ermanti. Estética da criasão verbal. São Paulo: Martins Fontes, 2003.

CAPOTE, Truman. $A$ sangue frio. São Paulo: Companhia das Letras, 2003.

CONNERY, Thomas B. Discovering a literary form. In: CONNERY, Thomas B. (org.). A sourcebook of American Literary Journalism. New York: Greenwood Press, 1992, p.3-37.

COSSON, Rildo. Fronteiras contaminadas. Brasília: Editora Universidade de Brasília, 2007.

Románce-reportágem: o gênero. Brasília/São Paulo: Editora Universidade de Brásília/I'mprensa Oficial do Estado, 2001.

ERBOLATO, Mário. Técnicas de codifficação em jornalismo. 5. ed. São Paulo: Ática, 2001.

FALASCHI, Celso Luiz. Identificasão de Narrativas e Caracteristicas Criativas no Jornalismo Impresso Diário Brasileiro. 2005. 440 f. Tese (Doutorado em Psicologia) - Fà́culdade de Psicologia, Pontificia Universidade Católica de Campinàs, Campinas.

FARACO, Carlos Alberto. Linguagem e Diálogo: as idéias lingüísticas do Círculo de Bakhtin. Curitiba: Criar Edições, 2003, p.48.

Autor e autoria. In: BRAIT, Beth (org.). Bakbtin, Conceitos-chave. São Paulo: Editora Contexto, 2005.

FONSECA, Isabel de Assis. Jornalismo literário em cordel: por um jornalismo genuinamente brasileiro. Conectiva, v.1, n.7, p.4162, jul./dez. 2006.

GERALDI, João Wanderley. É possível investir nas enunciações, sem as garantias dos enúnciados já firmados? In: MANFRIN, Aline Maria Pacífico et al. Veredas Bakbtianas - de objetos a sujeitos. São Carlos: Pedro \& João Editores, 2006, v. 1, p. 129-139.

. A diferença identifica. A desigualdade deforma. Percursos bakhtinianos de construção ética e estética. Freitas, Souza e Kramer (orgs.). Ciências bumanas e pesquisa: leitura de Mikbail Bakbtin. 
São Paulo: Cortez, 2003, p.39-56.

KERRANE, Kevin (org); YAGODA, Ben (org). The art of fact. New York: Simon \& Schuster, 1997.

LIMA, Edvaldo Pereira. Páginas Ampliadar. São Paulo: Manole, 2004.

MACHADO, Irene. Gêneros discursivos. In: BRAIT, Beth (org.). Bakebtin, conceitos-chaves. São Paulo: Ed. Contexto, 2005.

MAGNLHÃES, Mário. No jornalismo, a morte é masculina. Observatório da Imprensa, 6 nov. 2007. Disponivel em: http://observatorio.ultimosegundo.ig. com.br/artigos.asp?cod $=458 \mathrm{VOZ001}$ Acesso em: 28 abr. 2008 .

MAILER, Norman. O super-homem vai ao supermercado. São Paulo: Companhia das Letras, 2006.

MIOTELLLO, Valdemir. Ideologia. In: BRAIT, Beth. (org.). Bakhtin, conceitor-chaver. São Paulo: Ed. Contexto, 2005.

MELO, José Marques de. Teoria do jornalisimo - Identidades brasileiras. São Paulo: Paulus, 2006.

OLIVEIRA, Ana Paula Silva; PASSOS, Mateus Yurj. Joe Sacco: Jornalismo literário em quadrinhos. In: CONGRESSO BRASILEIRO DE CIÊNCIAS DA COMUNICAÇÑO, 29. 2006, Brasília. Anars. São Paulo: Sociedade Brasileira de Estudos Interdisciplinares da Comunicaçào, 2006.

PAIVA, Fred Melo. Carissima Eliana. O Estado de S. Panto, São Paulo, 12. jun 2005. Aliás, p.J8.

PASSOS, Mateus Yuri. Reportagem cientifica e humanização: duas propostas em jornalismo literário. Conectiva, v.1, n.7, p.103-136, jul./dez. 2006.

PASSOS, Mateus Yuri; ORLANDINI, Romulo A. Contando a história do presente: principios para uma caracterização estrutural do jornalismo literário. In: CONGRESSO BRASILEIRO DE CIËNCIAS DA COMUNICAÇÃO, 30., 2007, Santos. Anais. São Paulo: Sociedade Brasileira de Estudos Interdisciplinares da Comunicação, 2007.

PENA, Felipe. Jornalismo hiterário. São Paulo: Contexto, 2006.

RESENDE, Fernando. Textmaçöes - Ficçio e fato no Nono Jornalismo de Tom IWolfe. São Paulo: Annablume, 2002.

ROSS, Lillian. Reporting back - notes on jommalism. New York: Counterpoint, 2002.

S1LVESTRI, Kátia Vanessa Tarantini. Diz-sensu: contra-império e diferença deste a ação lingiuistica. 2006. 188 f. Disssertação (Mestrado em Lingǘstica) - Centro de Educação e Cièncias Humanas, Universida- 
de Federal de São Carlos, São Carlos.

SIMS, Norman (org.); KRAMER, Mark (org.). Literary Journalism - a new collecion of the best american nonfiction. New York: Ballantine, 1995, p.3-19.

SAVIANI REY, Luiz Roberto. A crônica é jornalística e brasileira. Campinas: Lince, 2007.

SODRÉ, Muniz; FERRARI, Maria Helena. Técnica de reportagem - Notas sobre a narrativa jornalística. 4. ed. São Paulo: Summus, 1986.

SUZUKI JR.; Matinas (org.). O livro das vidas. São Paulo: Companhia das Letras, 2008.

WOLFE, Tom. Radical cbique e o novo jornalismo. Tradução de José Rubens Siqueira. São Paulo: Companhia das Letras, 2005.

VIEIRA, Willian. Milton Domingos - Ou Carlitos, Charles Chaplin de Jundiaí. Folba de S. Paulo, São Paulo, 6 abr. 2008. Folha Cotidiano, p.12. Disponivel em: http://www1.folha.uol.com.br/fsp/ cotidian/ff0604200811.htm. Acesso em: 25 abr. 2008.

VILAS BOAS, Sérgio. Perfis: e como escrevê-los. São Paulo: Summus, 2003. 